\title{
Coagulopathy of Coronavirus Disease 2019: A Case Series
}

\author{
Jonathan Arifputra ${ }^{1 *}$, Harlinda Haroen ${ }^{2}$, Linda Wilhelma Ancella Rotty ${ }^{2}$, Pearla Fidei Cindy Lasut ${ }^{2}$, Cecilia Hendratta ${ }^{2}$ \\ ${ }^{1}$ Department of Internal Medicine, Faculty of Medicine, Sam Ratulangi University, Prof. dr. R. D. Kandou Hospital, Manado, \\ Indonesia; ${ }^{2}$ Division of Hematology Medical Oncology, Department of Internal Medicine, Faculty of Medicine, Sam Ratulangi \\ University, Prof. dr. R. D. Kandou Hospital, Manado, Indonesia
}

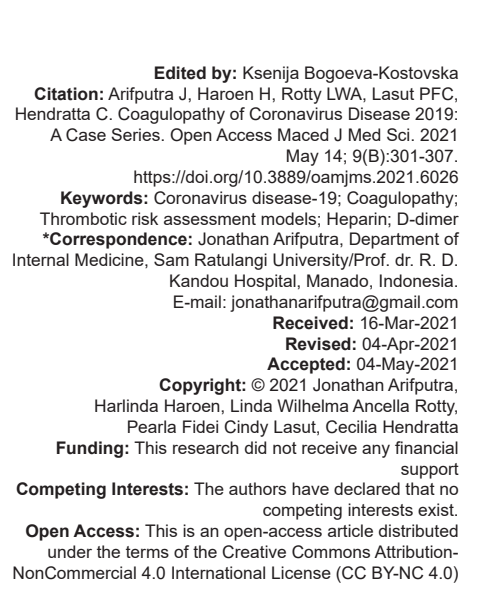

\section{Abstract}

BACKGROUND: In Coronavirus disease 2019 (COVID-19), the main manifestations were fever, cough, and anosmia.

AIM: We aimed to investigate coagulopathy and disseminated intravascular coagulation in severe COVID-19 patients.

METHODS: Five cases of COVID-19 with coagulopathy have been reported

RESULTS: All patients presented with various main complaints such as fever, cough, shortness of breath, and diarrhea. An increase in D-dimer value was found in all cases, with an increase of 4-5 times from the upper limit of normal. All patients were evaluated with the IMPROVE-VTE and PADUA thrombotic risk assessment models. Thromboprophylaxis with low molecular weight heparin LMWH intensive dosage was given to four patients. However, one patient was not given thromboprophylaxis because of the high risk of bleeding. All cases were not given longterm thromboprophylaxis after the patients were discharged from the hospital. All hospitalized COVID-19 patients can be considered to give thromboprophylaxis unless contraindicated. Thromboprophylaxis is preferable to use LMWH with a dose adjusted to the severity of COVID-19. Administration of thromboprophylaxis after hospitalization may be considered in patients who have thromboembolic risk factors.

CONCLUSION: More research is being encouraged to increase understanding of the prevention and treatment of thrombotic complications of COVID-19.

\section{Introduction}

Near the end of 2019, a type of pneumonia caused by the severe acute respiratory syndrome coronavirus 2 (SARS-CoV-2) virus was found in Wuhan, China, which later became known as Coronavirus Disease 2019 (COVID-19). COVID-19 has been declared as a global pandemic by $\mathrm{WHO}$ at the end of March 2020. The SARS-CoV-2 virus is a member of Coronaviridae family, much like SARS-CoV and Middle East respiratory syndrome coronavirus viruses that can cause severe respiratory distress [1], [2].

Viral pneumonia is the predominant manifestation of COVID-19. COVID-19 often presents with common infection symptoms such as fever, cough, and anosmia. However, based on several studies, coagulopathy and disseminated intravascular coagulation (DIC) are also quite commonly seen in severe COVID-19 patients. Based on the autopsy, deep vein thrombosis was found in 7 out of 12 COVID19 patients $(58 \%)$ with lung emboly complication in 4 patients (33\%). Tang et al. reported that $71.4 \%$ of COVID-19 patients that died had fulfilled DIC criteria, while only $0.6 \%$ of patients that recovered had fulfilled the criteria [3], [4], [5], [6].
COVID-19 is characterized by severe inflammation known as cytokine storm, which is identified by high levels of Interleukin-1, tumor necrosis factor, and other pro-inflammatory cytokines. This inflammation leads to thrombosis through several mechanisms such as activation of endothelial cells, thrombocytes, monocytes, factor VIla, and disruption of fibrinolysis pathway and normal anticoagulant function [7], [8].

Coagulopathy in COVID-19 is not a diathesis toward bleeding but rather points toward prothrombotic DIC with the increased level of D-dimer, high level of fibrinogen together with low anti-thrombin, and high incidence of venous thromboembolism and lung congestion with microvascular thrombosis. D-dimer has been reported multiple times as a biomarker associated with disease severity and as a predictor for worse prognosis. A tremendous amount of attention has been given to anticoagulant strategy to prevent or treat COVID-19 patients, both in hospitalization and outpatient settings [9], [10], [11].

The purpose of this case series is to raise awareness about coagulopathy condition and thromboprophylaxis in COVID-19. 


\section{Case Report}

\section{Patient 1}

A 58-year-old woman came to the hospital through the emergency room and was later hospitalized in isolation ward. The patient came with complaints of cough, shortness of breath, and anosmia for 4 days before being admitted to the hospital. The patient also had a fever for 1 week before being admitted to hospital. The patient had a history of hypertension for 20 years and dyslipidemia. The patient routinely consumes lisinopril and atorvastatin. Physical examination showed the patient was moderately ill and compos mentis. Blood pressure was $116 / 64 \mathrm{mmHg}$, heart rate was 91 times/ min, respiratory rate was 22 times/min, temperature was $37.2^{\circ} \mathrm{C}$, and oxygen saturation was $92 \%$ with $\mathrm{O}_{2} 3$ liter per minute $(\mathrm{Ipm})$ through nasal cannula. Chest X-ray showed bilateral pneumonia. Electrocardiogram (ECG) was normal. Nasopharynx swab showed positive reverse transcription-polymerase chain reaction (RT-PCR) result for COVID-19. Laboratory result on the $1^{\text {st }}$ day of hospitalization: D-dimer $0.27 \mu \mathrm{g} / \mathrm{mL}$, prothrombin time (PT) $13.3 \mathrm{~s}$, activated partial thromboplastin time (aPTT) $35.3 \mathrm{~s}$, international normalized ratio (INR) 0.72 , and thrombocyte count $585,000 / u L$. The patient was treated with antibiotic levofloxacin $750 \mathrm{mg} /$ day. On the $7^{\text {th }}$ day, the patient complained her dyspnea was worsening. Another chest X-ray was taken and showed severe bilateral pneumonia. D-dimer was increased into $2.0 \mu \mathrm{g} / \mathrm{mL}$ and C-reactive protein (CRP) was $48 \mathrm{mg} / \mathrm{L}$. Dyspnea did not improve with $\mathrm{O}_{2} 2-4 \mathrm{lpm}$ through nasal cannula. Thrombosis risk was evaluated with IMPROVE-VTE and PADUA score and risk of bleeding was evaluated with IMPROVE bleeding score. In this patient, the IMPROVE-VTE score was 0 (low risk), PADUA score was 4 (high risk), and IMPROVE bleeding score was 5.5 (low risk). The patient was given subcutaneous enoxaparin 4000 IU every $12 \mathrm{~h}$. D-dimer and CRP evaluation were $0.75 \mu \mathrm{g} / \mathrm{mL}$ and $<6 \mathrm{mg} / \mathrm{L}$ after 5 days enoxaparin was given. At this point, the patient no longer complained about dyspnea. Enoxaparin was stopped at the patient's request and replaced with rivaroxaban $10 \mathrm{mg} / 24 \mathrm{~h}$ for the next 14 days. Chest X-ray showed improvement of pneumonia. The patient was discharged after a negative RT-PCR result for COVID-19 and no clinical symptoms observed in Figure 1.

\section{Patient 2}

A 54-year-old man came to the hospital through the emergency room. The patient came with the main complaint of watery stool, up to 10 times/day, since 1 week before being admitted to the hospital. Fever and shortness of breath were denied. The patient had a history of lung neuroendocrine cancer and has undergone chemotherapy 5 times. The last chemotherapy

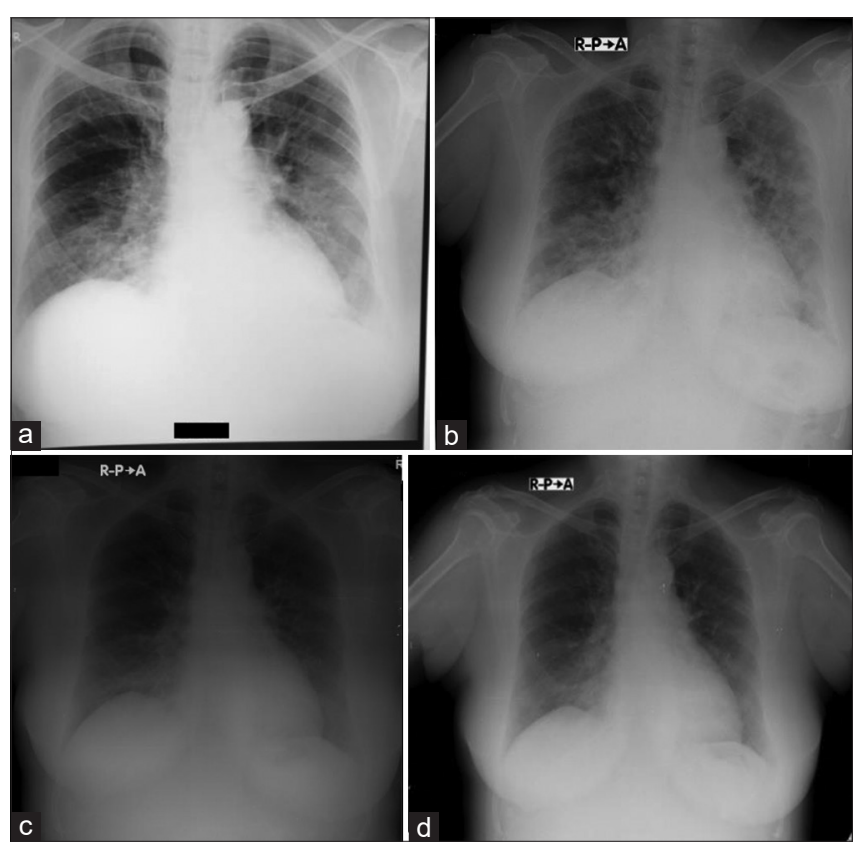

Figure 1: Chest $X$-ray of patient 1: (a) $1^{\text {st }}$ day of admission; (b) $7^{\text {th }}$ day of hospitalization; (c) $12^{\text {th }}$ day of hospitalization; (c) the last day of hospitalization

session was 1 year ago. The patient also had a history of untreated hepatitis B. On physical examination showed that the patient was moderately ill and compos mentis. His blood pressure was $120 / 80 \mathrm{mmHg}$, heart rate was $110 \mathrm{times} / \mathrm{min}$, respiratory rate was 20 times $/ \mathrm{min}$, temperature was $36.1^{\circ} \mathrm{C}$, and oxygen saturation was $98 \%$ without oxygen supplementation. Chest X-ray showed bilateral pneumonia. ECG was normal. Nasopharynx swab showed positive RT-PCR result for COVID-19. On the $2^{\text {nd }}$ day of hospitalization, his laboratory data showed D-dimer $2.11 \mu \mathrm{g} / \mathrm{mL}$, PT $23.1 \mathrm{~s}$, aPTT $47.3 \mathrm{~s}$, INR 2.24, thrombocyte count 380,000/uL, and CRP $24 \mathrm{mg} / \mathrm{L}$. The patient was treated with antibiotic levofloxacin $750 \mathrm{mg} /$ day. Thrombosis risk was evaluated with IMPROVE-VTE and PADUA score, and risk of bleeding was evaluated with IMPROVE bleeding score. In this patient, the IMPROVEVTE score was 2 (moderate risk), PADUA score was 7 (high risk), and IMPROVE bleeding score was 7 (high risk). Enoxaparin 4000 IU was not given because there was a high risk for bleeding. On the $7^{\text {th }}$ day, D-dimer evaluation was $0.8 \mu \mathrm{g} / \mathrm{mL}$. The patient was discharged after negative RT-PCR result for COVID-19 and no clinical symptoms observed in Figure 2.

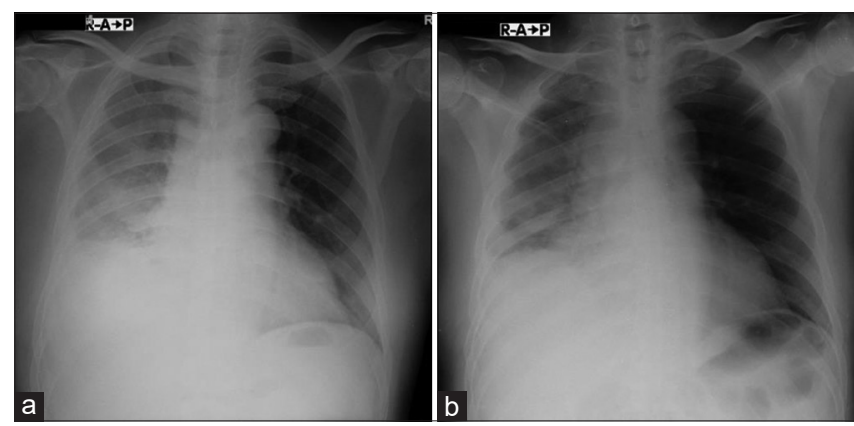

Figure 2: Chest $X$-ray of patient 2: (a) $1^{\text {st }}$ day of admission; (b) the last day of hospitalization 


\section{Patient 3}

A 77-year-old man came to the hospital through the emergency room. The patient came with main complaints of cough and fever for 3 days before admission. Shortness of breath and history of any previous illness was denied; however, the patient had a history of contact with the COVID-19 patient. Physical examination showed that the patient was moderately ill and compos mentis. His blood pressure was 134/70 $\mathrm{mmHg}$, heart rate was 88 times/min, respiratory rate was 20 times/min, temperature was $36.2^{\circ} \mathrm{C}$, and oxygen saturation was $99 \%$ without oxygen supplementation. Chest X-ray and ECG were normal. Nasopharynx swab revealed positive RT-PCR results for COVID-19. The patient was treated with azithromycin $500 \mathrm{mg} / 24 \mathrm{~h}$ and hydroxychloroquine $400 \mathrm{mg} / 12 \mathrm{~h}$. On the $7^{\text {th }}$ day, the patient complained of dyspnea and oxygen saturation dropped to $90 \%$. The patient was given $\mathrm{O}_{2} 10 \mathrm{lpm}$ through non-rebreathing mask and dexamethasone $5 \mathrm{mg} / 24 \mathrm{~h}$. Azithromycin and hydroxychloroquine were replaced with levofloxacin $750 \mathrm{mg} / 24 \mathrm{~h}$. Because of the patient's increasing oxygen demand $\left(\mathrm{PaO}_{2} / \mathrm{FiO}_{2} 44\right)$, the patient was referred to the intensive care unit (ICU) for further treatment, but the patient and his family refused. On the $8^{\text {th }}$ day, D-dimer, PT, INR, aPTT, and thrombocyte count were $2.23 \mu \mathrm{g} / \mathrm{mL}, 12.5 \mathrm{~s}, 23.8 \mathrm{~s}, 0.95$, and 274,000/uL Thrombosis risk was evaluated with IMPROVE-VTE and PADUA score, and risk of bleeding was evaluated with IMPROVE bleeding score. In this patient, the IMPROVE-VTE score was 1 (low risk), PADUA score was 5 (high risk), and IMPROVE bleeding score was 5.5 (low risk). Enoxaparin 4000 IU was administered every 12 h subcutaneously. Re-evaluation was done 7 days after enoxaparin was first administered. Dyspnea had improved and D-dimer value was $1.96 \mu \mathrm{g} / \mathrm{mL}$. Enoxaparin 4000 was continued and given every $24 \mathrm{~h}$ until the $14^{\text {th }}$ day after it was first administered. D-dimer value on the $14^{\text {th }}$ day was $1.7 \mu \mathrm{g} / \mathrm{mL}$, and the patient no longer had dyspnea and oxygen need had decreased because of this, enoxaparin was stopped. The patient was discharged after negative RT-PCR result for COVID19 and no clinical symptoms observed in Figure 3.

\section{Patient 4}

A 57-year-old man came to the hospital through the emergency room and hospitalized in ICU isolation room later. The patient came with main complaints of fever for 6 days before admission. Fever was accompanied by cough and shortness of breath that started to appear 4 days before admission. The patient had a history of hypertension and dyslipidemia, currently under treatment with amlodipine $10 \mathrm{mg}$, valsartan $80 \mathrm{mg}$, and atorvastatin $40 \mathrm{mg}$. Physical examination showed that the patient was moderately ill and compos mentis. His blood pressure was 160/100 $\mathrm{mmHg}$, heart rate was 102 times/min, respiratory rate was 22 times $/ \mathrm{min}$, temperature was $38.5^{\circ} \mathrm{C}$, and oxygen saturation was $92 \%$ without oxygen supplementation.

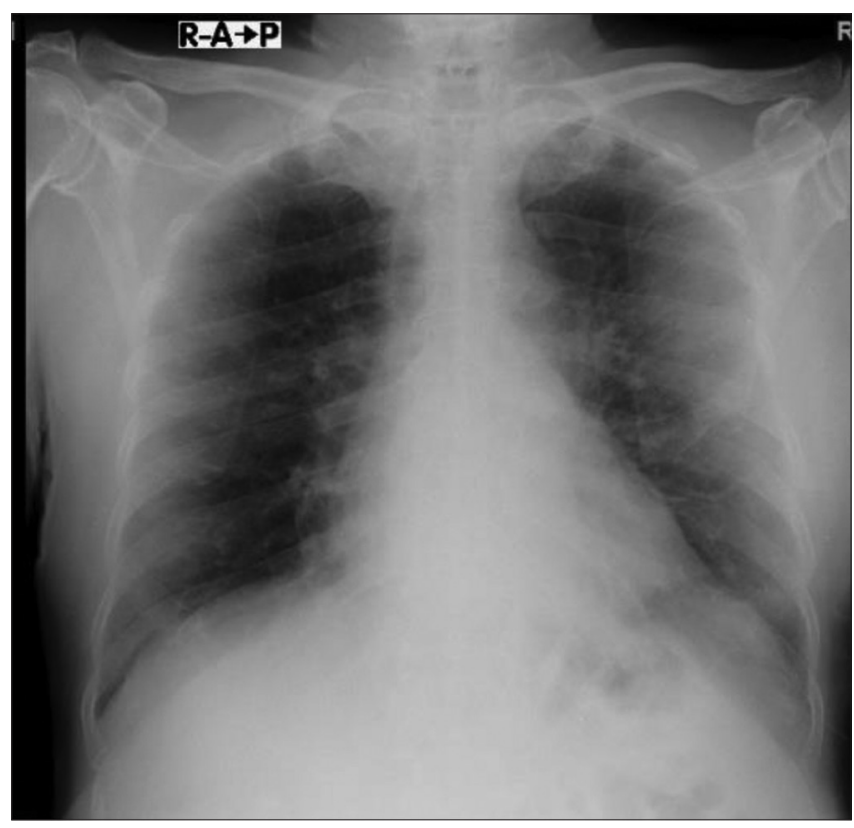

Figure 3: Chest $X$-ray of patient 3: (a) $1^{\text {st }}$ day of admission

Chest X-ray revealed bilateral basal pneumonia. ECG result showed sinus tachycardia (100 times/min), normal axis. Nasopharynx swab showed positive RT-PCR result for COVID-19. On the $1^{\text {st }}$ day of hospitalization, laboratory data showed D-dimer $13.51 \mu \mathrm{g} / \mathrm{mL}$, PT $12.1 \mathrm{~s}$, aPTT $37.4 \mathrm{~s}$, INR 1.07 , and thrombocyte $111,000 / \mathrm{uL}$. The patient has treated with remdesivir loading dose $200 \mathrm{mg}$ and continued with $100 \mathrm{mg} / 24 \mathrm{~h}$ for 5 days. Thrombosis risk was evaluated with IMPROVE-VTE and PADUA score, and risk of bleeding was evaluated with IMPROVE bleeding score. In this patient, the IMPROVE-VTE score was 0 (low risk), PADUA score was 4 (high risk), and IMPROVE bleeding score was 4.5 (low risk). Enoxaparin 4000 IU was administered every $12 \mathrm{~h}$ subcutaneously. D-dimer evaluation was $20 \mu \mathrm{g} / \mathrm{mL}$ on the $3^{\text {rd }}$ day after enoxaparin was given. At this point, the patient was still experiencing dyspnea. On the $7^{\text {th }}$ day of enoxaparin treatment, D-dimer value was $0.93 \mu \mathrm{g} / \mathrm{mL}$, and dyspnea has improved. Another D-dimer evaluation was done on the $14^{\text {th }}$ day of enoxaparin treatment, D-dimer value was $0.51 \mu \mathrm{g} / \mathrm{mL}$, and enoxaparin was stopped. Chest X-ray re-evaluation showed improvement of pneumonia. The patient was discharged after negative RT-PCR result for COVID-19 and no clinical symptoms observed in Figure 4.

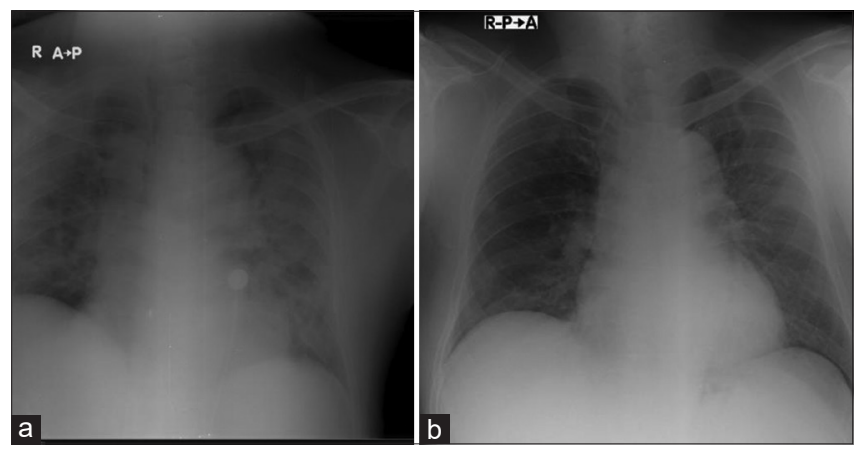

Figure 4: Chest X-ray of patient 4: (a) $1^{\text {st }}$ day of admission; (b) $14^{\text {th }}$ day of hospitalization 


\section{Patient 5}

A 53-year-old man came to the hospital through the emergency room and hospitalized in ICU isolation room later. The patient came with a loss of consciousness 1 day before admission. The patient also experienced fever and cough for 4 days before admission. The patient had a history of hypertension and type 2 diabetes with low compliance toward treatment. Physical examination showed that the patient was severelyilland delirium. His blood pressure was $127 / 78 \mathrm{mmHg}$, heart rate was 105 times/min, respiratory rate was $30 \mathrm{times} / \mathrm{min}$, temperature was $38.4^{\circ} \mathrm{C}$, and oxygen saturation was $87 \%$ with oxygen $15 \mathrm{lpm}$ through non rebreathing mask. Patient's bodyweight was $160 \mathrm{~kg}$, height was $150 \mathrm{~cm}$, and body mass index (BMI) was $36.7 \mathrm{~kg} / \mathrm{m}^{2}$. Chest X-ray revealed bilateral pneumonia and cardiomegaly. ECG showed sinus tachycardia (102 times/min) and left ventricular hypertrophy. Nasopharynx swab showed positive RT-PCR result for COVID-19. Since the $\mathrm{PaO} / \mathrm{FiO}_{2}$ value was 71.5 , a central venous catheter was inserted, and the patient was placed on ventilator. Laboratory showed D-dimer $2.2 \mu \mathrm{g} / \mathrm{mL}$, CRP 24 mg/L, PT 13.9 s, aPTT 35.2 s, INR 1.03, and thrombocyte $165,000 / \mathrm{uL}$. The patient has treated with remdesivir loading dose $200 \mathrm{mg}$ and continued with $100 \mathrm{mg} / 24 \mathrm{~h}$ for 10 days. Thrombosis risk was evaluated with IMPROVE-VTE and PADUA score, and risk of bleeding was evaluated with IMPROVE bleeding score. In this patient, the IMPROVE-VTE score was 1 (low risk), PADUA score was 5 (high risk), and IMPROVE bleeding score was 4.5 (low risk). The patient was given subcutaneous enoxaparin $4000 \mathrm{IU}$ every $12 \mathrm{~h}$. D-dimer evaluation was $3.1 \mu \mathrm{g} / \mathrm{mL}$ on the $3^{\text {rd }}$ day after enoxaparin administration. On the $4^{\text {th }}$ day of enoxaparin treatment, the patient started having hematemesis and melena, thus enoxaparin was stopped. D-dimer was $0.45 \mu \mathrm{g} / \mathrm{mL}$ on the $5^{\text {th }}$ day of hospitalization. The patient was extubated on the $7^{\text {th }}$ day of hospitalization. Chest X-ray re-evaluation showed improvement of pneumonia. The patient was discharged after a negative RT-PCR result for COVID-19 and no clinical symptoms observed Figure 5.

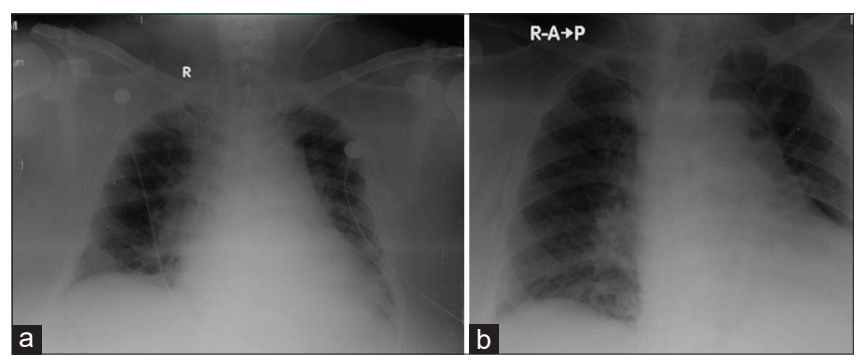

Figure 5: Chest $X$-ray of patient 5: (a) $1^{\text {st }}$ day of admission; (b) $7^{\text {th }}$ day of hospitalization

\section{Discussion}

One of the characteristics of COVID-19 is its wide array of clinical manifestations and outcomes, ranging from asymptomatic to organ failure and death. Coagulopathy in COVID-19 manifests as a prothrombotic state, in which bleeding rarely happened to patients, even in the DIC state. Thromboembolism incidence in SARSCoV-2 infection has been garnering much attention. One study involving 3000 hospitalized COVID-19 patients showed that the incidence rate of thromboembolism was $16 \%$, in which $13.6 \%$ happened in ICU, and $3.6 \%$ happened in the regular isolation ward. Cui et al. reported that thrombosis incidence on COVID-19 patients in the ICU could reach up to $20-30 \%$ [12], [13], [14]. In this case series report, the patient in case 3 was supposed to be referred to ICU. However, the patient refused and was treated in the regular isolation ward. In this case series report, three patients were hospitalized in the regular isolation ward, and two patients in ICU.

Coagulopathy evaluation on COVID-19 patients can be challenging because of the lack of data and clear clinical or coagulopathy parameters that could be used as a basis for treatment, and there is also a concern of COVID-19 transmission during diagnostic procedures. Significant laboratory findings in COVID-19 coagulopathy showed slightly prolonged PT and aPTT, which suggests a high state of thrombosis with elevated levels of fibrin exchange and normal or decreased thrombocyte count. In the case report, all the patients had normal thrombocyte count, except patient 4. Prolonged PT and aPTT were only seen in patient 2.

Elevated D-dimer on admission is associated with an increase in disease severity in COVID-19. D-dimer levels of $0.5 \mu \mathrm{g} / \mathrm{mL}$ or higher were found in $59.6 \%$ of patients with severe COVID-19 compared to $43.2 \%$ of patients with mild infection. D-dimer value between 1001 and $2500 \mathrm{ng} / \mathrm{mL}$ (95\% confidence interval, 1.26-7.31) has a risk of 3.04 times higher for thrombosis complication, and D-dimer $>2500 \mathrm{ng} / \mathrm{mL}$ has a risk of 6.79 times higher. Cui et al. reported that D-dimer level also correlates with venous thromboembolism risk. D-dimer $3.0 \mu \mathrm{g} / \mathrm{mL}$ has a $70 \%$ sensitivity, $96.7 \%$ specificity, and $87.5 \%$ predictive positive value [11], [16], [18]. Three patients in the case report had increased D-dimer value 4-5 times from its normal value. This increase in D-dimer value is associated with increased severity, as has been seen in patients 1, 3, and 4. Suspected, probable, or confirmed COVID-19 patients that are hospitalized should be evaluated for coagulation function tests (D-dimer, PT, aPTT, fibrinogen, and thrombocyte count). The result from these laboratory tests can give valuable information about the patient's prognosis. Elevated D-dimer is associated with a worse prognosis, while decreased fibrinogen is associated with DIC. Both of these things 
can happen in 7-11 days after COVID-19 symptoms first appeared or 4-10 days after hospitalization [10], [16], [19], [20], [21], [22].

COVID-19 patients have multiple thromboembolism risk factors such as bed rest, obesity, other infection and comorbidities, advanced age, and primary disease. The release of inflammatory mediators, hormones, and immunoglobulins in large amounts, especially in severe or critical COVID19 infection, can also cause thromboembolism. Furthermore, mechanical ventilators, central venous catheterization, and surgery can cause injury to the vascular endothelial wall. A combination of all these factors can cause thromboembolism or lung embolism because of migrating thrombus. Therefore, thromboembolic risk assessment should be done for all hospitalized COVID-19. Risk assessment can be done using standard thromboembolic risk scoring such as PADUA, IMPROVE-VTE, or International Society of Thrombosis and Hemostasis (ISTH) DIC [10], [16], [19], [20], [21], [22]. Thromboembolic risk assessment for all patients in this case report was done using PADUA and IMPROVE-VTE score. ISTH DIC score was not used because fibrinogen level was not evaluated in all five patients.

One study in China reported that $40 \%$ of COVID-19 patients in hospital had high thromboembolic risk based on PADUA score, but the use of thromboprophylaxis was not mentioned in the study. British society of hematology recommends the use of ISTH DIC as a prognostic indicator during treatment. Tang et al. found that ISTH DIC score $\geq 5$ can be used to predict poor prognosis, as it is found in $71.4 \%$ of patients that died. On the other hand, only $0.6 \%$ of patients that recovered had ISTH DIC score $\geq 5$ [5], [23].

Optimal thromboembolic stratified risk algorithm for COVID-19 patients' needs further study before it can be implemented, including the use of D-dimer as a predictor for thrombosis incidence and prognosis.

At present, coagulopathy management on COVID-19 is based on several studies, case reports, and experience and opinions from various institutions. There were many differences between institutions in their approach to prevent and treat coagulopathy in COVID-19 because of the absence of high-quality data that can serve as a guideline. Regardless of which approach is used, it is recommended to balance the risk of thrombosis and bleeding before administering anticoagulant therapy.

One study reported a thromboembolism incidence of $25 \%$ and mortality rate of $40 \%$ among hospitalized patients with severe COVID-19. Furthermore, ICU patients had a higher thromboembolic rate because of the limited mobility of patients. Another study found that the incidence of venous thromboembolism and artery thromboembolism was
$27 \%$ and $3.7 \%$, respectively, in 184 COVID-19 patients in ICU. ICU patients have an overall worse prognosis. However, given the high thromboembolic rate in the initial report, the "universal" use of thromboprophylaxis for all hospitalized patients with COVID-19, for now, might be a better strategy than an individual thromboembolic risk assessment approach [10], [16], [19], [20], [21], [22]. The patients in this case report were evaluated using an individual thromboembolic risk assessment approach.

The hospitalized patient can be considered for thromboprophylaxis therapy with standard-dose unfractionated heparin (UFH) or low molecular weight heparin (LMWH). Apart from its anti-thrombotic effect, heparin might also have anti-inflammatory, anticomplement, and antiviral effects that might be useful in COVID-19 treatment. Heparin inhibits neutrophil activation, binds inflammatory cytokines, and reduces endothelial cell activation. The experimental model had also shown that heparin directly binds spike protein from SARS-CoV, preventing virus entry into the cells. In a subset of COVID-19 patients that have D-dimer $>3.0 \mu \mathrm{g} / \mathrm{mL}$ (6 times the normal upper limit), there was a statistically significant decrease in mortality rate in heparin users compared to non-users $(32.8 \%$ vs. $52.4 \%, p=0.017)$. LMWH has several advantages compared to UFH, such as once-daily versus 2- or 3-times injection and fewer thrombocytopenia incidence compared to heparin [10], [16], [19], [20], [21], [22], [24]. Patients $1,3,4$, and 5 received LMWH therapy for thromboprophylaxis purposes, while patient 2 was not given LMWH because of the high risk for bleeding. Although several Direct-Acting Oral Anticoagulants (DOAC) have been approved as prophylaxis, the use of these agents should be considered carefully in COVID19 patients that are also receiving immunosuppressants, anti-virus, and other experimental therapies because of the potential to disrupt DOAC. Patient 1 was given DOAC after 5 days of LMWH use.

Many institutions have adopted thromboprophylaxis protocol using LMWH regimen with intensive dosage. This decision is based on the evidence that showed an increase in thrombogenicity in COVID-19 patients, especially in those with severe infection. Thromboprophylaxis intensive dose (e.g., half of LMWH therapeutic dose once daily or LMWH prophylaxis dose twice daily) should be considered for patients with additional risk factors (e.g., BMI $>30 \mathrm{~kg} / \mathrm{m}^{2}$, history of vein thromboembolism, thrombophilia, cancer) and/or requiring ICU treatment and/or rapidly increasing D-dimer value, while also taking kidney function and risk of bleeding into account [10], [16], [19], [20], [21], [22]. Patients 1, 3, 4 , and 5 received an intensive dose of $L M W H$, which is $4000 \mathrm{IU} / 12 \mathrm{~h}$ subcutaneously because of their rapidly increasing D-dimer level and also because of the disease severity progression.

Patient 5 experienced a bleeding complication in the form of hematemesis after using LMWH for 
4 days. Bleeding is not a common manifestation in COVID-19 and usually occurs due to other causes such as trauma or the use of anticoagulant. Management approach of bleeding due to anticoagulant use in COVID-19 is similar to the one in non-COVID patients, such as the anticoagulant needs to be stopped, blood product transfusion if there is thrombocytopenia or hypofibrinogenemia, or other specific therapies like blood coagulation factor replacement [15].

In high-risk patients, hospital-associated thromboembolic risk can last up to 6 weeks after the patient is discharged. At least $60 \%$ of all thromboembolic incidence happened after patients were discharged from the hospital. The first 3 weeks are associated with a 5-fold increased risk of developing lung embolism. In a certain population where the risk of thromboembolism is high, and the risk of bleeding is low, thromboprophylaxis administration (LMWH intensive dose or DOAC such as rivaroxaban or betrixaban) for about 4 weeks after hospital discharge can reduce the risk of thromboembolism without significantly increasing the risk of bleeding. Recent data also showed that patients with IMPROVE-VTE score $\geq 4$ with elevated D-dimer (>2 $\times$ normal upper limit) have a thromboembolic risk 3 times greater. In these patients, thromboprophylaxis is significantly beneficial. Despite the lack of data on COVID-19, long-term thromboprophylaxis with LMWH or DOAC could be considered for at least 2-6 weeks after hospital discharge to reduce the risk of bleeding on COVID-19 patients with an additional thromboembolic risk factor such as advanced age, treatment in ICU, cancer, history of a previous thromboembolic event, thrombophilia, immobility, elevated D-dimer $(>2 x$ normal upper limit), and IMPROVE-VTE score $\geq 4$ [10], [16], [19], [20], [21], [22]. In this case report, all five patients were not given thromboprophylaxis after being discharged.

The limitation of this case series was the small number of reported cases so that it cannot represent the population, and there were no non-COVID-19 cases as a comparison. During the COVID-19 pandemic, it is difficult to do all radio-diagnostic studies.

\section{Conclusion}

All hospitalized COVID-19 patients can be considered to give thromboprophylaxis unless contraindicated. Thromboprophylaxis is preferable to use LMWH with a dose adjusted to the severity of COVID-19. Administration of thromboprophylaxis after hospitalization may be considered in patients who have thromboembolic risk factors. More research, such as randomized control trials, is being encouraged to increase understanding of the prevention and treatment of thrombotic complications of COVID-19.

\section{References}

1. Zhu N, Zhang D, Wang W, Li X, Yang B, Song J, et al. A novel coronavirus from patients with pneumonia in China, 2019. N Engl J Med. 2020;382(8):727-33.

PMid:31978945

2. Shi Y, Wang G, Cai XP, Deng JW, Zheng L, Zhu HH, et al. An overview of COVID-19. JZhejiang Univ SciB. 2020;21(5):343-60. PMid:32425000

3. Jin Y, Yang H, Ji W, Wu W, Chen S, Zhang W, et al. Virology, epidemiology, pathogenesis, and control of covid-19. Viruses. 2020;12(4):372. https://doi.org/10.3390/v12040372 PMid:32230900

4. Iba T, Levy JH, Levi M, Thachil J. Coagulopathy in COVID-19. J Thromb Haemost. 2020;18:2103-9. https://doi.org/10.1111/ jth.14975

5. Tang N, Li D, Wang X, Sun Z. Abnormal coagulation parameters are associated with poor prognosis in patients with novel coronavirus pneumonia. J Thromb Haemost. 2020;18(4):844-7. https://doi.org/10.1111/jth.14768 PMid:32073213

6. Ahmed S, Zimba O, Gasparyan AY. Thrombosis in coronavirus disease 2019 (COVID-19) through the prism of Virchow's triad. Clin Rheumatol. 2020;39:2529-43. https://doi.org/10.1007/ s10067-020-05275-1

7. Ye $Q$, Wang $B$, Mao J. The pathogenesis and treatment of the "Cytokine Storm" in COVID-19. J Infect 2020;80(6):607-13.

PMid:32283152

8. Iba T, Levy JH, Connors JM, Warkentin TE, Thachil J, Levi M. The unique characteristics of COVID-19 coagulopathy. Crit Care. 2020;24(1):360. https://doi.org/10.1186/s13054-020-03077-0 PMid:32552865

9. Al-Ani F, Chehade S, Lazo-Langner A. Thrombosis risk associated with COVID-19 infection. A scoping review. Thromb Res. 2020;192:152-60. https://doi.org/10.1016/j. thromres.2020.05.039

PMid:32485418

10. Spyropoulos AC, Levy JH, Ageno W, Connors JM, Hunt BJ, Iba T, et al. Scientific and Standardization Committee communication: Clinical guidance on the diagnosis, prevention, and treatment of venous thromboembolism in hospitalized patients with COVID-19. J Thromb Haemost. 2020;18(8):1859-65. https://doi. org/10.1111/jth.14929

PMid:32459046

11. Al-Samkari H, Leaf RS, Dzik WH, Carlson JC, Fogerty AE, Waheed A, et al. COVID-19 and coagulation: Bleeding and thrombotic manifestations of SARS-CoV-2 infection. Blood. 2020;136(4):489-500. https://doi.org/10.1182/ blood.2020006520

PMid:32492712

12. Akima $S$, McLintock $C$, Hunt BJ. RE: ISTH interim guidance to recognition and management of coagulopathy in COVID-19. J Thromb Haemost. 2020;18(8):2057-8. https://doi.org/10.1111/ jth.14853

PMid:32302442

13. Klok FA, Kruip MJ, van der Meer NJ, Arbous MS, Gommers DA Kant KM, et al. Incidence of thrombotic complications in critically ill ICU patients with COVID-19. Thromb Res. 2020;191:145-7. https://doi.org/10.1016/j.thromres.2020.04.013 PMid:32291094

14. Cui S, Chen S, Li X, Liu S, Wang F. Prevalence of venous thromboembolism in patients with severe novel coronavirus pneumonia. J Thromb Haemost. 2020;18(6):1421-4. https://doi. 
org/10.1111/jth. 14830

PMid:32271988

15. Cuker A, Peyvandi F. Coronavirus Disease 2019 (COVID-19): Hypercoagulability UpToDate; 2019. Available from: https:// www.uptodate.com/contents/coronavirus-disease-2019-covid19-hypercoagulability?search=coagulopathycovid\&source=sea rch_result\&selectedTitle=1 20\&usage_type=default\&display rank $=1 \#$ H00. [Last accessed on 2020 Sep 12]. https://doi. org/10.1007/s42399-021-00854-y

16. Mucha SR, Dugar S, McCrae K, Joseph D, Bartholomew J, Sacha GL, et al. Coagulopathy in COVID-19: Manifestations and management. Cleve Clin J Med. 2020;87(8):461-8. https:// doi.org/10.3949/ccjm.87a.ccc024

PMid:32409435

17. Guevara-Noriega KA, Lucar-Lopez GA, Nuñez G, RiveraAguasvivas L, Chauhan I. Coagulation panel in patients with SARS-CoV2 infection (COVID-19). Ann Clin Lab Sci. 2020;50(3):295-8. PMid:32581015

18. Vidali S, Morosetti D, Cossu E, Luisi ML, Pancani S, Semeraro V, et al. D-dimer as an indicator of prognosis in SARS-CoV-2 infection: A systematic review. ERJ Open Res. 2020;6(2):002602020. https://doi.org/10.1183/23120541.00260-2020 PMid:32685436

19. Zhai Z, Li C, Chen Y, Gerotziafas G, Zhang Z, Wan J, et al. Prevention and treatment of venous thromboembolism associated with coronavirus disease 2019 infection: A consensus statement before guidelines. Thromb Haemost.
2020;120(6):937-48. https://doi.org/10.1055/s-0040-1710019 PMid:32316065

20. Connors JM, Levy JH. COVID-19 and its implications for thrombosis and anticoagulation. Blood. 2020;135(23):2033-40. https://doi.org/10.1182/blood.2020006000

PMid:32339221

21. Langer F, Kluge S, Klamroth R, Oldenburg J. Coagulopathy in COVID-19 and its implication for safe and efficacious thromboprophylaxis. Hamostaseologie. 2020;40(3):264-9. https://doi.org/10.1055/a-1178-3551

PMid:32498097

22. Barnes GD, Burnett A, Allen A, Blumenstein M, Clark NP, Cuker A, et al. Thromboembolism and anticoagulant therapy during the COVID-19 pandemic: Interim clinical guidance from the anticoagulation forum. J Thromb Thrombolysis. 2020;50(1):72-81. https://doi.org/10.1007/s11239-020-02138-z PMid:32440883

23. Wang T, Chen R, Liu C, Liang W, Guan W, Tang R, et al. Attention should be paid to venous thromboembolism prophylaxis in the management of COVID-19. Lancet Haematol. 2020;7(5):e3623. https://doi.org/10.1016/s2352-3026(20)30109-5 PMid:32278361

24. Buijsers B, Yanginlar C, Maciej-Hulme ML, de Mast Q, van der Vlag J. Beneficial non-anticoagulant mechanisms underlying heparin treatment of COVID-19 patients. EBioMedicine. 2020;59:102969. https://doi.org/10.1016/j.ebiom.2020.102969 PMid:32853989 